\title{
NOTAS PARA PENSAR LA INFANCIA EN LA ARGENTINA (1983-2001): FIGURAS DE LA HISTORIA RECIENTE
}

\section{Sandra Carli*}

RESUMO: $\mathrm{O}$ artigo analisa, numa perspectiva historiográfica, o impacto da história recente argentina na vivência da infância de crianças de diferentes extratos sociais. Tendo como recorte o fim do regime militar, na década de 80 , busca-se apreender como o processo de globalização, entendido como fenômeno não apenas econômico, mas sócio-cultural teve efeito na transformação da experiência infantil. Por um lado, a globalização provocou a intensificação de uma cultura de consumo que tomou a criança como objeto privilegiado do mercado. Foram introduzidos novos produtos que tiveram como efeito a homogeneização da cultura infantil. Por outro, tal homogeneização incide sob crianças de diferentes extratos sociais e possibilidades de acesso ao consumo, num pais pauperizado. Assim e que a homogeneização cutural fez-se acompanhar pela produção de novas desigualdades e heterogeneização da condição social das criancas.

Palavras-chave: Infância; Argentina; Globalização; Desigualdade.

\section{NOTES TO REFLECT UPON CHILDHOOD IN ARGENTINA (1983-2001): CHARACTERS OF A RECENT HISTORY}

ABSTRACT: This paper analysis, through a historiographic perspective, the impact of the recent Argentine history in the way children from different social stratification enjoy their childhood. Having the end of the military regime as a landmark, in the 1980's, our goal is to apprehend how the globalization process, perceived not only as an economic but also sociocultural phenomenon, resulted in the transformation of the childhood experience. On the one hand, globalization arouses the intensification of a culture of consumption, which regards children as a key target in a privileged market. New products have been introduced generating the homogenization of the culture of childhood. On the other hand, such homogenization has affected children of different social stratification and their access to consumption, in an extremely poor country. This way, the cultural homogenization went along with the production of new inequalities and the heterogenization of children's social conditions.

Keywords: Childhood; Argentine; Globalization; Inequality.

\footnotetext{
* Doctora en Educación (Universidad de Buenos Aires); Profesora titular regular de la Facultad de Ciencias Sociales de la Universidad de Buenos Aires; Investigadora Independiente del Consejo Nacional de Investigaciones Científicas y Técnicas con sede en el Instituto de Investigaciones Gino Germani. E-mail: scarli@fibertel.com.ar
} 


\section{Introducción}

El ciclo que va de la postdictadura al año 2000 ha dejado en la niñez argentina las huellas de cambios globales y locales que lo diferencian de otros ciclos históricos. El traumático pasaje del modelo de sociedad integrada de principios de los años 70 al modelo de sociedad crecientemente polarizada y empobrecida de fines de los años 90, en el marco de la expansión mundial del capitalismo financiero, permite constatar que el tránsito por la infancia como un tiempo construido socialmente asume hoy otro tipo de experiencias respecto de generaciones anteriores y da lugar a nuevos procesos y modos de configuración de las identidades. La cuestión de la infancia se constituye, entonces, en un analizador privilegiado de la historia reciente y del tiempo presente ${ }^{1}$ que permite indagar los cambios materiales y simbólicos producidos en la sociedad argentina, pero a la vez es también un objeto de estudio de singular importancia en tanto la construcción de la niñez como sujeto histórico ha adquirido notoria visibilidad.

Las décadas del 80 y del 90 del siglo XX en la Argentina fueron décadas de estabilidad democrática y al mismo tiempo de aumento exponencial de la pobreza. Desde una perspectiva de historia de la infancia podemos decir que este ciclo histórico, que es posible analizar retrospectivamente luego del impacto de la crisis del $2001^{2}$, muestra a la vez tendencias progresivas y regresivas: si por un lado se produjeron avances en el reconocimiento de los derechos del niño y una ampliación del campo de saberes sobre la infancia, el conocimiento acumulado no derivó en un mejoramiento de las condiciones de vida de los niños y en este sentido estos perdieron condiciones de igualdad para el ejercicio de sus derechos. En buena medida la infancia como experiencia generacional se tornó imposible de ser vivida según los parámetros de acceso e integración social del ciclo histórico anterior, pero se convirtió en signo en una sociedad crecientemente visual que puso en escena los rostros de esa imposibilidad y los rasgos emergentes de las nuevas experiencias infantiles.

Una mirada desde el presente ilumina el ciclo histórico reciente y nos permite en forma preliminar esbozar una serie de hipótesis:

I) La niñez devino en un verdadero laboratorio social en un proceso histórico dominado por la aceleración del cambio científico-tecnológico, la desaparición gradual del mundo del trabajo, la globalización econó- 
mica y tecnológica y la mundialización de la cultura. Decimos laboratorio social porque los niños nacidos en la Argentina durante los años 80, y más aun en los años 90, crecieron en un escenario en profunda mutación convirtiéndose en testigos y en muchos casos en víctimas de la desaparición de formas de vida, pautas de socialización, políticas de crianza. En el caso argentino el pasaje del viejo país al nuevo país (FEIJOO, 2001) marcado por el desempleo, la movilidad descendente y el aumento de la pobreza, produjo una mayor distancia en la experiencia de generaciones contemporáneas en cuanto a condiciones de vida y horizontes de futuro y un aumento notorio de la desigualdad social dentro de la misma generación infantil. Se produjo, por otra parte, el pasaje de una sociedad infantil caracterizada por la mezcla social a una sociedad crecientemente marcada por las diferencias sociales. Pasaje traumático ${ }^{3}$ que permite identificar distintas temporalidades de la historia argentina en el presente, desde el niño que en un carro tirado por un caballo recorre por la noche la gran metrópolis y que recuerda el siglo XIX, hasta el niño que accede a las más modernas tecnologías del siglo XXI desde la privacidad del hogar familiar.

II) En este escenario en franca mutación, la niñez adquirió visibilidad al mismo tiempo que se produjo cierta invisibilización de las consecuencias trágicas sobre los niños del cambio de estructura social en la Argentina. En esta nueva visibilidad colaboró el reconocimiento de los derechos del niño, que tuvo como efecto producir cierta universalización de la identidad infantil. A la vez que el niño "sujeto de derecho" fue enunciado de un discurso de democratización de las instituciones de menores y de interpelación a los gobiernos nacionales, devino en una figura globalizada en un escenario de aumento inédito de la vulnerabilidad de la infancia en la Argentina. Los medios en tanto espacios de la visibilidad y del reconocimiento social (BARBERO, 2003a, p. 108) generaron en estas décadas productos que colaboraron de diversa forma con una estetización o espectacularización dramática de la experiencia infantil.

III) Se produjo en este ciclo histórico un proceso de creciente mercantilización ${ }^{4}$ de los bienes y servicios para la infancia que incluyen un espectro amplio y variado que va desde la explosión de los maxikioskos y las jugueterías hasta la privatización comercial del festejo de cumpleaños infantiles. Bienes y servicios que adquirieron valor de cambio, valor de uso y valor de signo en un escenario de acceso material desigual de la población infantil al consumo y de debilitamiento general de los espacios públi- 
cos y de la interpelación estatal a la niñez. El proceso que algunos autores denominan de macdonalización de la sociedad como nueva racionalidad económica (RITZER, 1996) intervino en la circulación de nuevo tipo de signos que asumen aspectos polémicos - en un contexto de aumento de la desigualdad - por la combinatoria de deseos, necesidades e investimientos afectivos que el consumo infantil genera y su impacto en la constitución de las identidades sociales (GARCÍA CANCLINI, 1999).

IV) Esta creciente mercantilización fue contemporánea del debilitamiento del estado-nación como cuerpo de pertenencia imaginaria durante estas décadas (SIDICARO, 2000, p. 12), dejando atrás en el tiempo aquella potente y a la vez polémica interpelación estatal de la población infantil de los años 40 y 50 del siglo XX (véase CARLI, 2005). Si bien en el caso de la niñez no hubo un debilitamiento de la acción estatal en sentido estricto - en tanto en la década del 90 se diseñaron políticas educativas y sociales activas sin discutir aquí su sentido - se produjo la escisión entre cierta retórica del discurso estatal referido a la niñez y las políticas económicas que operaron un despojo sin precedentes de las generaciones futuras.

Las políticas de infancia pensadas como políticas en las que se pone en juego la representación del niño en el sentido de "hablar en nombre de" otro ausente en el momento de la representación (CARLI, 2003a) a la vez que se especializaron dando lugar a otro tipo de presencia en el organigrama y en la agenda estatal, encarnaron la crisis de la relación entre representantes y representados con el telón de fondo de la reforma del estado y el cambio profundo de la estructura social. Maestros, que a lo largo de los años 90 ocuparon la escena política hablando "en nombre de" los alumnos del sistema educativo, y más tarde familiares, que hablan "en nombre de" sus hijos víctimas de situaciones de muerte o maltrato, comenzaron a llevar a adelante políticas de representación de niños y adolescentes que indican tanto la crisis de las mediaciones estatales como el componente político de los vínculos educativos y filiales.

V) Las identidades infantiles se vieron afectadas por procesos de homogenización y heterogenización socio-cultural. Mientras ciertos elementos indican formas de uniformización de la cultura infantil como resultado de una cultura global sobre la infancia, el aumento de la desigualdad social generó una mayor e irreversible distancia entre las formas de vida infantil, si solo atendemos al contrastre entre el countrie y la villa como habi- 
tats paradigmáticos (vease SVAMPA, 2001; DEL CUETO, 2003; ARIZAGA, REDONDO, 2004). Si bien es posible realizar una lectura totalizadora de la identidad infantil en el período teniendo en cuenta ciertas marcas globales y la permanencia de dispositivos modernos como la escuela, es necesario un trabajo de destotalización de las identidades (HALL, 2003) que tenga en cuenta los procesos de apropiación diferencial (DE CERTEAU, 1996, p. 40) de los niños. Ello no implica dejar de destacar el predominio de elementos de estandarización y de estereotipos en la oferta cultural-comercial para niños que sesga los modos de apropiación, recordando a su vez la mayor permeabilidad del niño frente a los relatos ${ }^{5}$. Las condiciones desiguales para el acceso provocaron no solo el aumento de diferencias, sino también la presencia de nuevas formas de distinción social a través del consumo infantil, distinciones que parecen retrotraernos a la etapa previa a la ampliación del acceso al consumo que se produce en los años 40 y 50 del siglo XX en la Argentina.

VI) El carácter simétrico o asimétrico de la relación entre niñosadultos resulta una clave de lectura de fenómenos y procesos de este ciclo histórico. La interacción asimétrica entre niños y adultos (GALENDE, 1994) que en el terreno psíquico se liga con las diferencias entre la sexualidad infantil y la sexualidad adulta, asume desde el punto de vista sociocultural formas y contenidos variados dando cuenta de la dislocación y/o inversión de las posiciones de los sujetos en la cadena generacional o del cuestionamiento de sus fundamentos, en un período atravesado por debates referidos a la "crisis de autoridad" en la familia, en la escuela y en la sociedad en general y por la presencia de fenómenos como el aumento de la violencia en los vínculos intergeneracionales, el crecimiento del trabajo infantil y hasta la expansión de la pedofilia en el país. Las fronteras entre las edades y el sentido social y cultural de la prohibición, están permeados por la crisis de un imaginario de continuidad, de pasaje intergeneracional para la sociedad en su conjunto y de alcances de la responsabilidad adulta.

Estas hipótesis orientarán nuestra exploración de la relación entre infancia y sociedad, infancia y educación, infancia y políticas. Lo haremos a partir de la idea de figuras que permite recuperar las imágenes constituidas por los discursos (de los medios, de la pedagogía, de la política, etc.). La experiencia cultural contemporánea es también una experiencia crecientemente audiovisual en la que el proceso de construcción visual de lo social requiere abordar la realidad también como realidad de 
representaciones (BARBERO, 2003b). La realidad infantil nos habla así a través de su representación, pero también de lo que en ella está ausente.

\section{Las figuras del niño de la calle y del niño consumidor entre lo local y lo global}

Durante la dictadura militar la niñez fue convertida en botín de guerra como parte de una política de secuestro y a la vez encerrada en el ámbito familiar como consecuencia de una interpelación estatal que satanizó la peligrosidad del espacio público y los beneficios del ámbito privado. La idea de la nación como conjunto de familias que formaba parte del discurso militar (FILK, 1997, p. 44-45) sedimentó también nuevas ideas sobre la relación entre infancia y sociedad. El período democrático que comienza en 1983 con la asunción de Raúl Alfonsín se inaugura con: a) las evidencias de un genocidio, que incluyó la sustracción de menores, rompiendo con las formas de continuidad de la sociedad, en la medida en que la eliminación del otro (los desaparecidos) incluyó la apropiación por parte del poder militar de sus descendientes; b) las evidencias del cierre de un ciclo económico que comienza a impactar en forma notoria sobre la población infantil provocando, también, rupturas en la continuidad de la cadena generacional, y c) un debate acerca de las formas y sentidos de la representación política y social de la población infantil, en el contexto de rearmado de los partidos políticos y del estado, de la nueva presencia de organismos no gubernamentales nacionales e internacionales y de los emergentes movimientos sociales.

La recuperación e institucionalización de la democracia durante los años 80 se acompañó con un proceso de empobrecimiento del país que distintos autores califican como inédito para la Argentina. La población infantil en su conjunto comenzaba a experimentar un lento y gradual deterioro económico respecto de la generación de sus padres, y dejaba de representar la mezcla social prototípica del país impidiendo su reproducción en el futuro. Es en los años 90 que comienza a constatarse que la crisis de finales de la década y los procesos de ajuste que la acompañaron "han afectado con especial dureza a la infancia, socavando sus condiciones de salud, nutrición y educación” y que la recomposición argentina se producía "en el contexto de un país que se empobrece" (MINUJíN, 1995, p. 17-21). En ese proceso se destacó el deterioro económico de los secto- 
res medios y la aparición de los llamados "nuevos pobres", dando lugar a una "pobreza adquirida", no heredada, fenómeno que condujo a nuevas conceptualizaciones sobre la pobreza que destacaron su "intersticialidad" (FEIJOO, 1995, p. 233) y su "transversalidad” (GONZALEZ, 1995, p. 295).

Una mirada desde el presente indica que dos décadas de democracia en la Argentina dejaron como saldo un retroceso inédito en el bienestar infantil, destacándose la dimensión regresiva de este ciclo histórico y sus efectos traumáticos sobre las trayectorias de niños y familias. Si como ha señalado Hobsbawm, "el pasado documentado cambia a la luz de la historia subsiguiente" (1998, p. 236) una mirada del ciclo inmediato anterior se torna mítica: en la década del 70 el $5 \%$ de la población vivía en hogares con ingresos bajo la línea de pobreza, en la década del 80 subió al $12 \%$, a partir de 1998 se incrementa notablemente superando el $30 \%$ y en 2002 llegó al 51\% (SIEMPRO, 2002). La década del 90, que a partir de la asunción anticipada en 1989 de Carlos Saul Menem como presidente, había comenzado con promesas de estabilidad monetaria, recomposición salarial y aumento de la producción, terminaría con un cuadro recesivo alarmante. La llegada del siglo XXI mostró así el país real: en octubre del año 2001 el 55,6\% de los menores de 18 años eran pobres y prácticamente el $60 \%$ de los pobres eran menores de 24 años, mostrando que la Argentina como sociedad "ha roto las bases más elementales para la efectiva vigencia de un compromiso social democrático” (CTA, 2002).

El proceso de empobrecimiento de amplios sectores de la sociedad argentina se vio acompañado por procesos de concentración de la riqueza y polarización social, como resultado de la redistribución regresiva de los ingresos ${ }^{6}$ y del impacto en el empleo y en la producción nacional de la apertura al capital extranjero, de las importaciones y de las privatizaciones. Mientras un sector amplio de la población infantil vivió las consecuencias del empobrecimiento, que sumó a los sectores medios en descenso, un pequeño sector vivió un rápido mejoramiento de sus condiciones de vida.

Esta notoria transformación del tejido social de la Argentina durante estas décadas permite comprender las nuevas figuras de la infancia argentina: el niño de la calle y el niño consumidor, figuras que condensan transformaciones globales y locales y encarnan la nueva estructura social del país. Mientras la emergencia de la problemática de la niñez en la calle es resultado de los procesos de empobrecimiento económico-social, aumen- 
to del desempleo y ajuste que conducen a la explosión de la pobreza infantil como fenómeno estructural durante la década del 90, el despliegue de la problemática del consumo infantil resulta del proceso de transnacionalización de la economía, la estabilidad monetaria y la convertibilidad que propicia nuevas practicas económico-culturales de los niños y sus familias. La niñez en la calle encarnó la continuidad e irreversibilidad de la expulsión social de amplios sectores y el consumo infantil las aspiraciones de las clases medias-altas en el nuevo escenario socioeconómico de los años 90, aunque permeando un imaginario de acceso al consumo del conjunto de los sectores sociales.

Si bien la problemática de la niñez en la calle tiene sus antecedentes más remotos en la mendicidad infantil en el BsAs de fines del siglo XIX, es en la década del 80 del siglo XX cuando la presencia de niños en la calle se torna un hecho social de relevancia y va modificando notoriamente el espacio urbano, cada vez más similar a las imágenes de otros países latinoamericanos.

Publicaciones de entonces, tanto del sector público como de organismos no gubernamentales, señalaron la ampliación del universo social de los llamados "menores" y cómo la pobreza de las familias comenzaba a atravesar de forma dramática la vida cotidiana infantil. La figura del niño de la calle, que dará lugar a programas estatales en la década del 80, va dando forma a la industria de su institucionalización, produciéndose desde los '70 hasta fines de los '80 un aumento del ingreso de niños y adolescentes a instituciones de minoridad por causas sociales y un aumento a partir de 1981 del ingreso por causas delictivas, que se interpretó como una puesta a la luz del filicidio encubierto durante la dictadura (LIWSKI, 1988, p. 42).

Distintos testimonios ${ }^{7}$ indican que el fenómeno de los chicos en la calle, que comenzó como parte de un proceso de deterioro social de las familias en los 80, se agudizó a partir de la segunda mitad de la década del 90, luego de haberse producido "la transformación de los niños y las mujeres en la variable de ajuste de las situaciones de empobrecimiento de los hogares" (LIWSKI, 1991, p. 187). En los años 90 el desarrollo de acciones y organismos públicos dedicados al tema y de organismos no gubernamentales e internacionales, a partir de la Convención Internacional de los Derechos del Niño, permiten comprender la magnitud del fenómeno y la institucionalización del mismo. 
La problemática del consumo y la figura del niño consumidor resulta una metáfora de la inclusión material o imaginaria, y no es antinómica de la figura del niño de la calle, en tanto el consumo supone también un horizonte imaginado, excediendo los procesos de identificación con los objetos las posibilidades económicas de apropiación del consumidor ${ }^{8}$. Se entiende aquí por consumo "el conjunto de procesos socioculturales en que se realizan la apropiación y los usos de los productos" (GARCÍA CANCLINI, 1999, p. 34) formando parte del ciclo de producción y de circulación de bienes.

Si bien todo consumo es un hecho cultural, el consumo cultural sería aquel "conjunto de procesos de apropiación y uso de productos en los que el valor simbólico prevalece sobre los valores de uso y de cambio o donde al menos estos últimos se configuran subordinados a la dimensión simbólica" (GARCÍA CANCLINI, 1999, p. 42). En relación al consumo cultural infantil interesa destacar la expansión del mercado de productos para niños, la expansión de la TV satelital y sus producciones derivadas, la expansión de la informática, la producción de nuevo tipo de espectáculos infantiles, que provocaron una nueva configuración comercial y estética de la producción cultural; cabe mencionar también la diversificación de la oferta privada de educación. Una encuesta nacional hecha en 1999 mostraba entre otros resultados que el 71,2\% de los hogares tenían televisión por cable, el 37\% frecuentaba shopings y el 28\% tenia computadora en la casa' (FRAGA, 1999, p. 33). Estos datos permiten a su vez pensar en dos rasgos señalados por García Canclini, la creación de relaciones terciarias y la institución de sujetos en estructuras sociales ampliadas: en este caso, la relación de los niños con nuevos agentes (medios, internet, mercado en general) que exceden los vínculos primarios (familia) y secundarios (instituciones educativas) y la inscripción de los mismos en un mundo global de referencias.

Las figuras del niño de la calle y del niño consumidor tradujeron en experiencias vitales y en procesos socio-culturales, la complejización y heterogeneización de la estructura social de la Argentina (MINUjÍN, 1999). Indican por un lado las consecuencias de la destrucción del modelo productivo y del empleo sobre los procesos de deterioro familiar y social de amplios sectores que genera la expulsión y/o salida de los hijos a la calle y por otro la centralidad económica que un mercado global y transnacional adquiere a través de productos y bienes de diverso tipo, 
dando forma a un nuevo paisaje cultural a disposición de los niños de distintos sectores sociales a través centralmente de la televisión comercialpublicitaria ${ }^{10}$ y de la venta directa en los comercios. Deterioro social-consumo ampliado-acceso desigual al consumo se combinaron de modos paradójicos. Si la exclusión social que caracterizó a la década debe tomarse como un concepto relativo y no absoluto, que constituye la contrapartida de la inclusión y que varía en el tiempo y en el espacio (MINUjíN, 1999, p. 57), las figuras del niño de la calle y del niño consumidor se constituyen en espejo, como caras contrastantes de la polarización social creciente.

En la investigación histórico-educativa predominó una visión totalizadora de la niñez, en buena medida sesgada por un tipo de sociedad con niveles de homogeneidad e integración social, sin fracturas sociales extremas, y con un sistema educativo con capacidad inclusiva e igualadora (CARLI, 2002). Las transformaciones producidas en las décadas recientes demandan desmontar esa visiòn totalizadora y considerar el impacto de la desigualdad social en la producción de diferencias en el cuerpo social infantil. Podemos hipotetizar que las identidades infantiles comenzaron a presentar por un lado marcas del proceso de diferenciación social, que distanció dramáticamente la experiencia de niños de distintos sectores sociales, y por otro signos de homogeneización cultural resultantes del impacto en los gustos, lenguajes y necesidades de una cultura ${ }^{11}$.

\section{De la problemática de la filiación a las figuras del niño peligroso y del niño víctima en los medios}

Una mirada horizontal de las diferencias dentro de una misma generación de niños provee elementos para comprender lo que Arendt denominó la "sociedad infantil"; una mirada vertical permite apreciar las articulaciones entre la sociedad adulta y la sociedad infantil, los vinculos intergeneracionales que son una dimensión de análisis del lazo social. La cuestión de la infancia constituye un analizador de esos vínculos y las características que presentan en la sociedad argentina contemporanea. Mientras la dictadura militar convirtió el secuestro y sustracción de identidad de los hijos de desaparecidos en una forma de violencia directa capaz de instituir simbolicamente un orden social nuevo al cortar la vin- 
culación entre engendradores y engendrados, durante las décadas posteriores se produjo una puesta a la luz de situaciones y conflictos vinculados con la identidad y la filiación de los hijos de desaparecidos apropiados durante la dictadura.

Pero también durante estas décadas se produce la explosión de conflictos específicos entre adultos y niños/adolescentes - con violencia física y en distintos escenarios (espacio público, instituciones educativas, hogares de menores, etc.) - que mostró la complejidad de la nueva trama socio-cultural. Si bien estos conflictos son prototípicos de un ciclo histórico caracterizado por la tan mentada "crisis de autoridad", por el desplazamiento hacia modalidades más flexibles de crianza y educación y por la modificación de las fronteras de edad como resultado de cambios culturales y tecnológico-mediáticos con impacto en la cultura de las generaciones (SARLO, 1994; MARGULIS, 1996; entre otros), podemos sostener que en el caso argentino esto se ha combinado con los efectos residuales de la dictadura militar (1976-1983), con la ruptura del lazo social producto del cambio de modelo económico y con el abandono de responsabilidades básicas del estado. El aumento exponencial de los conflictos violentos en las relaciones sociales entre adultos y niños/jóvenes (ver SVAMPA, 2001) y de las muertes violentas en las ultimas décadas (BONALDI, 2002), se entrama a su vez con las consecuencias de la reducción del universo material y cultural del trabajo como espacio de inclusión, de pertenencia imaginaria y de definición de horizontes de futuro para las familias y sus hijos.

En los medios este crecimiento de la violencia se hace notorio a través del tratamiento de la problemática de los "menores". Mientras en la década del 80 el tema "menores" victimas o actores de delitos irrumpe en la prensa gráfica, es en los 90 que se torna tema también de la televisión.

Una exploración de la prensa gráfica del período 1983-2001² muestra el crecimiento de situaciones de violencia contra menores (niños y adolescentes) a cargo de sujetos adultos e instituciones y en distintos escenarios, dando cuenta de la complejidad de los vínculos intergeneracionales postdictadura. Se multiplicaron las situaciones violentas al mismo tiempo que resultaron visualizadas por los medios de comunicación. Es possible leer modalidades y vínculos del conjunto de la sociedad en su conjunto, que remite a la combinación de fenómenos ligados con la salida de la dictadura militar, las nuevas identidades juveniles, el deterioro de 
las familias y ciertos anacronismos evidentes de las instituciones educativas. La repetición de casos en el tiempo largo expresa ya tendencias más sedimentadas de la sociedad argentina reciente.

Los medios y en particular la prensa gráfica dieron visibilidad social a estos conflictos y acontecimientos y la cuestión de la infancia, y en particular de los menores, pasó a ser un tema "noticiable" con impacto en la opinión pública. A medida que el imaginario de época se fue alejando de la denuncia de los crímenes de la dictadura en los años 80 y que el escenario social de los 90 comenzó a mostrar las consecuencias de la expulsión social de niños y jóvenes, los medios comenzaron a dar visibilidad al delito infantil y juvenil. Si bien las estadísticas indican el progresivo aumento de delitos cometidos por menores y la baja en la edad del delito, así como una tendencia mas general a la judicialización de la niñez en la Argentina (GUEMUREMAN; DAROQUI, 2001), los medios colaboraron en la exposición de un fenómeno a medida que fue creciendo la pobreza y la inseguridad en el país en la segunda mitad de la década del 90. Esto se ha reflejado en el desplazamiento del género policial a un lugar central de la agenda periodística, género que se caracteriza por la exclusión de la ciudadanía al predominar un tratamiento simplificado y reduccionista de la realidad en el tratamiento de las noticias (MARTINI, 2002). Las dudas que en distintas notas de opinión sobre el tema se esgrimen sobre las estadísticas que fundamentan la tesis del aumento del delito juvenil, son un indicador más de la complejidad de este carácter noticiable y sensacionalista del fenómeno.

Las figuras del niño peligroso y del niño víctima, son figuras que irrumpen en los medios como construcciones sociales que condensan las grandes transformaciones de estas décadas, instalándose como verdaderas representaciones sociales en las que en forma común - más allá de las posiciones ideológicas de los productores - la asimetría es borrada, nega$\mathrm{da}^{13}$ y por tanto el lugar de responsabilidad del adulto. En la construcción mediática de la figura del niño "peligroso" (por sospecha o por cometer un delito) se filia al "menor" en la historia del delito, apelándose a la necesidad de dispositivos de control de diverso alcance, cuestión que puede detectarse en los debates producidos en relación a la legislación de menores o a la baja de la imputabilidad del menor.

Mientras la figura del niño peligroso es utilizada en forma sensacionalista para generar polémica, miedo social o rechazos conservadores, 
borrando las posibilidades de comprensión, de historización biográfica o de impugnación de las instituciones, a partir de mirar los actos desde un puro presente y desde sus efectos; la figura del niño victima ${ }^{14}$ es tratada de tal manera de promover conductas de compasión social y formas de consenso activo o pasivo, aunque canalizando mayores demandas sociales de aplicación de justicia. En el tratamiento mediático de los hechos vinculados con niños hay en la mayor parte de los casos un borramiento de la polisemia personal, de los matices de cada historia individual, de las tragedias de cada pequeña historia: las figuras de infancia se ofrecen vaciadas de historia, ubicadas en un lugar "otro". Recordemos que el genero policial en los medios es uno de los espacios significativos mas fuertes para construcción y consolidación de representaciones de los “otros" diferentes y de representaciones de amenaza e inseguridad (MARTINI, 2002, p. 88). En este caso los "otros diferentes" son niños y adolescentes, colocados en un lugar de externalidad a la sociedad en su conjunto.

La visión social sobre la infancia en la Argentina está atravesada por esta construcción mediática, por esa construcción visual de la cuestión social que ha debilitado una polémica pública y una reapropiación colectiva de los horizontes de futuro de la población infantil en su conjunto.

\section{Las figuras del alumno:}

\section{entre el derecho privado familiar y la esfera pública}

Si recordamos aquí la tesis central de P. Ariès que plantea la estrecha relación entre escolarización y producción de infancia en la modernidad, podemos afirmar que las diversas crisis y transformaciones del sistema educativo durante las décadas del 80 y del 90 dieron lugar a una producción compleja, polémica y contradictoria del alumno, una figura moderna traducida en los rostros dispares y contrastantes de la Argentina postdictadura. El sistema educativo no puede ser analizado como un dispositivo panóptico que configura las identidades de los alumnos a partir de ciertas operaciones comunes, - mirada predominante y a la vez mítica del pasado educacional - sino que demanda un análisis de las formas y contenidos de la escolarización desde una perspectiva a la vez localizada y general y la producción de infancia en dichos espacios y tiempos. Si la heterogeneización de la estructura social de la Argentina no se 
divorcia de cierta heterogeneización en aumento del sistema educativo, hay que destacar también su impacto en la producción de la infancia como categoría social no homogénea. En nuestro caso señalaremos algunos ejes analíticos para estudiar estos fenómenos.

Durante la transición democrática la figura del alumno cristalizada en el sistema educativo debía ser revisada. Entonces, en el clima de revisión de la herencia dictatorial, diversas publicaciones señalaron la vigencia en el sistema educativo de concepciones paternalistas, autoritarias y asimétricas que redundaban en una "concepción del alumno no como sujeto de aprendizaje sino como objeto de enseñanza" y se asentaban en un "supuesto de la homogeneidad del alumnado", dando lugar a una crisis de los modelos de relación docente-alumno (AGUERRONDO, 1987). Se cuestionaba la homogeneidad del sujeto de la educación ante la evidencia de la inexistencia de un modelo único de niñez y la importancia de considerar las distintas experiencias de vida infantil (TEDESCO, 1983; AGUERRONDO, 1987).

Si el alumno debía ser mirado a partir de la pluralidad de experiencias infantiles, desde una perspectiva que retomara en el terreno pedagógico los nuevos saberes sobre la infancia, la crisis reproductiva del sistema educativo argentino postulada entonces por distintos especialistas (TEDESCO, 1983; PUIGGROS, 1986) indicaba su fracaso en la producción de un sujeto de la educación homogéneo, a pesar de la universalización de la enseñanza básica y del aumento en la proporción de la población que asistía a la escuela ${ }^{15}$. Un sistema atravesado por una creciente segmentación interna ya no generaba una experiencia de escolarización común a la población infantil.

Mientras las teorías sobre la infancia promovían una atención mayor a la singularidad del niño en la experiencia escolar, esta ultima perdía sus elementos unificadores. En el ciclo histórico que estamos analizando se produce la configuración de un campo de saberes sobre la infancia con aportes de distintas disciplinas (véase CARLI, 2003) que revierte sobre diverso tipo de interpretaciones sobre la categoría alumno; desde el constructivismo cuya expansión debe leerse como una experimentación teórico-didáctica propia del clima de época postdictatorial ${ }^{16}$ hasta las diversas líneas de la psicología y del psicoanálisis.

A esta heterogeneidad al interior del sistema educativo público debe sumarse el impacto del debate educación pública-educación privada 
en la perdida de condiciones de homogeneidad y en la creciente diferenciación de las figuras del alumno. La sanción de la Ley Federal de Educación en abril de 1993 destacaría la inclusión de los derechos de los educandos (título VIII, capitulo I, artículo 43), que fue el resultado de la Convención Internacional de los Derechos del Niño sancionada en 1990. El reconocimiento de derechos de los educandos debe evaluarse sin embargo junto con la inclusión en el texto de los derechos y deberes de los padres y de la familia y el peso notorio de la educación privada, que abre el juego a esta diferenciación.

La equiparación entre educación publica y educación privada a partir de que la ley estableciera las escuelas "de gestión pública” y escuelas “de gestión privada”, otorgó nueva legitimidad a la educación no estatal, invisibilizando los datos que indicaban la importancia de la cobertura estatal de la matrícula escolar ${ }^{17}$. Junto con la definición de los "servicios educativos de gestión privada", la ley define a la familia como "agente natural y primario de la educación", reconociendo el derecho de los padres a la elección de la educación de sus hijos. Una lectura retrospectiva de la ley indica que la valorización de la educación privada y de los derechos de los padres colaboró en el aumento de la diferenciación socio-educativa, teniendo en cuenta que la sociedad argentina arribó al siglo XXI con los peores indicadores de pobreza infantil y que la educación estatal fue tema de conflictos notorios durante la década vinculados con el financiamiento y la situación salarial de los maestros. La aparición de nuevos modelos de socialización educativa en los countries como posición de las clases medias en ascenso (SVAMPA, 2001) que indican la producción de nuevas distinciones culturales a través de la educación, resultantes de la polarización social y de la creación de nuevos proyectos y estilos de vida, y la presencia en el debate público de posiciones de defensa de diversas formas de libre elección de escuela (NARODOSWKI y otros, 2002) en un escenario de posibilidades crecientemente desiguales de elección para los sujetos sociales, deben considerarse como favorables a formas diferenciales de educación.

El notorio avance de la heterogeneidad estructural de la Argentina en la década del 90, mostraría tanto la inexistencia de condiciones equivalentes para la participación e implicación comunitaria y familiar y para generar alternativas autónomas como la colaboración en una mayor diferenciación ${ }^{18}$. La defensa de la autonomía escolar y de la desregulación 
estatal en un sistema educativo segmentado y heterogéneo y en una sociedad empobrecida en la que predominan distintas formas de guetización social, parece funcional tanto a una mayor diferenciación de las experiencias escolares como a la diferenciación desigual de las figuras del alumno. Más que la imitación de las estrategias educativas del sector privado (siempre más atento a las demandas de los padres para la producción de la oferta educacional) que el discurso favorable a la privatización propugnó, el sector público se encontraba más que nunca ante el desafío de fortalecer aquellos principios políticos capaces de generar una oferta común que instituyera condiciones mas equitativas para la producción de infancia, sin por ello negar la revisión y modernización que para entonces requería el funcionamiento estatal.

En relación con este mayor protagonismo de los padres y de la educación privada, debe analizarse también el peso de la noción de "educación básica" que en la ley desplazó la noción de educación pública. Si la noción de educación pública enfatizaba la responsabilidad estatal en el acceso a una educación común para todo niño y aludía a significados políticos y culturales propios de una tradición del siglo XX; la noción de educación básica tradujo en la normativa nacional la noción propiciada por el discurso del Banco Mundial, asociada a la educación formal, primaria e infantil, y ligada a la formación de competencias básicas (lectura, matemática, ciencias) ${ }^{19}$ y articulada a la equiparación entre gestión pública y privada de la educación. En la actualidad, ante las evidencias del aumento de la pobreza, se señala algo que era evidente muchos antes, que “...el problema de la educación básica no existe en forma singular, sino plural y diferenciado según el segmento social de que se trate" (TENTI FANFANI, 2000 , p. 2). La instalación acrítica de la idea de educación básica en el discurso de la Reforma Educativa de los años noventa, y en forma más amplia en el discurso de la educación, mas que propiciar una base común para la población infantil funcionó instalando un notorio cambio en el horizonte político-cultural del sistema educativo que formaba parte de la tradición educativa del país y negando las condiciones sociales necesarias para sostener - entre otras cosas - la extensión de la obligatoriedad escolar.

Si la educación pública durante buena parte del siglo XX había tenido por horizonte cultural la idea de emancipación social e igualdad de oportunidades acompañando la conformación de una sociedad integrada 
y la producción de un cierto status cultural homogeneo en la población infantil, la "educación basica" fue funcional a la restricción del imaginario de igualdad social de la educación publica ${ }^{20}$ y a una sociedad crecientemente segmentada como consecuencias de políticas económicas que fueron erosionando las posibilidades de sostenimiento familiar de la educación de los hijos.

Se produjo entonces a partir de la década del 90 otra producción de infancia por el sistema educativo. Mientras la educacion "básica" en el espacio de la educación estatal se convirtió para buena parte de la población infantil en una moratoria de la exclusión futura de esos niños y no el paso preparatorio y previo a una integración social promisoria al mundo del trabajo y la ciudadanía activa que demandaría un ciclo largo y más complejo de educación, en el espacio de la educación privada la noción de educación básica no asume las mismas implicancias restrictivas. La noción "básica" tiene desigual significación en el contexto de una sociedad no productiva con diversidad de ofertas escolares cada vez más orientadas por la demanda y menos por la direccionalidad política del estado en la construcción de una cultura común y con posibilidades de apropiación diferenciales por parte de niños y jóvenes. La idea de educación básica en su despliegue histórico desmintió su aspiración democratizadora en el discurso educativo de la época (proveer cierta educación común al conjunto de la población infantil) para revelar su sentido estratégico como espacio de contención social y de diferenciación educativa.

El desplazamiento hacia posiciones favorables a la educación privada y el debilitamiento del sentido público de la educación en los discursos de la época colaboró en el proceso de individualización del niño y de la infancia como colectivo social cada vez más segmentado, introduciendo un corte respecto de las perspectivas totalizadoras de otros ciclos históricos, ligándose a su vez con el pasaje de una cultura pública a una sociedad íntima (SENNET, 2002) en la que el virtual protagonismo adjudicado a los padres tiende a borrar la responsabilidad del estado sobre el bienestar del conjunto de la población infantil. Las figuras del alumno no corresponderían a partir de allí a un universo simbólico común, sino a mundos sociales particulares. Los debates actuales sobre el financiamiento no hacen más que cristalizar la deuda histórica del sistema democrático y de la sociedad política para con la sociedad infantil en su conjunto: el debate sobre el gasto público en educación se plantea como modo de compen- 
sar las realidades educativas crecientemente desiguales ${ }^{21}$ que se construyeron en la historia reciente.

La ecuación histórica fue que durante los años 90 una población infantil en proceso de empobrecimiento asistió a un sistema educativo mas segmentado y menos homogéneo en una sociedad crecientemente polarizada. Todos los datos mostraron que durante los años 90 el empobrecimiento de la sociedad argentina afectó especialmente a alumnos niños y jóvenes - agravandose a finales de la década - (CTA) y a maestros (Ctera-IIPEMV, 2001). El aumento de la matrícula escolar acompañó la realidad del incumplimiento de la obligatoriedad escolar (Ctera-IIPPMV, 2001; 2004) que la ley federal había pretendido extender a diez años ${ }^{22}$. La cuestión central no se plantea entonces en la enunciación de derechos y en la aspiración de extensión de la educación que planteó la ley, sino en la identificación de los actores responsables del servicio educativo y de las condiciones socio-económicas para el sostenimiento de la obligatoriedad escolar.

Publicaciones recientes coinciden en un diagnostico sobre el sistema educativo propiciando una mirada retrospectiva de las décadas recientes: la reforma educativa de la década del 90, mas que superar la homogeneidad cualitativa del sistema señalado a principios de los 90, provocó una mayor heterogeneidad. La idea de fragmentación se reitera en todos los estudios sobre el sistema educativo ensayando estrategias diversas para superarlo (PUIGGROS, 1997; TIRAMONTI, 2001; KESSLER, 2003; etc.), pero estando ausente una reflexión sobre la producción de infancia en este escenario.

Es necesario a partir de aquí repensar la tesis acerca del fin de la infancia moderna que planteó con lucidez la crítica posmoderna (LEWCOWICZ; COREA, 1999), aunque sin detenerse en las particularidades del proceso histórico local. El fin de la infancia moderna en la Argentina debería leerse como resultado de políticas que desmantelaron o vaciaron de sentido los signos del pasado como el delantal blanco o el acceso democrático de todos los niños a los mismos bienes educativos, signos que al ser leídos como homogeneizantes o disciplinantes no fueron reconocidos como portadores de representaciones de integración social ${ }^{23}$. Esa capacidad estatal-pública de producir una infancia con ciertos rasgos de homogeneidad fue productora en el largo plazo del siglo XX de trayectorias singulares y de identidades colectivas diversas, sino tenemos en cuen- 
ta los fenómenos que dan cuenta de la producción cultural y científica de la argentina, entre otros ejemplos. Reponer desde una perspectiva política el concepto de homogeneidad no implica desconocer la diversidad de experiencias infantiles, sino que implica aportar a una lectura crítica del aumento de la desigualdad en la historia reciente y plantear las políticas de infancia como espacio para un litigio por el acceso y disfrute del bien educación. Implica debatir tanto sobre las condiciones sociales y educativas desde las cuales se accede como las características materiales y simbólicas de ese bien "común”.

\section{Las figuras del niño carenciado y de los chicos del pueblo en la arena de la política}

La cuestión de la infancia constituye un analizador de los efectos de las culturas políticas sobre los horizontes de futuro de las generaciones infantiles. Interesa retomar aquí la definición de Landi (1988) que plantea que la definición de lo qué es y no es político en una sociedad en un momento dado es producto de los conflictos por la hegemonía entre los distintos sectores sociales y que la frontera entre lo político y lo no político es histórica y cambiante, no se restringe a ciertos enunciadores ni a un tema, sino que remite a relaciones intersubjetivas que forman parte de un orden determinado y a las relaciones en una cultura entre lo público y lo privado ${ }^{24}$.

Durante estas décadas se produjo el pasaje del protagonismo de los partidos políticos durante la transición democrática de los años 80 a la videopolítica de los años 90, que acompañó la crisis de representación de los partidos, la internacionalización de las políticas nacionales y la subordinación de la política a la economía del mercado (QUEVEDO, 1999; PORTANTIERO, 2000; SIDICARO, 2002). Durante la transición democrática fueron los partidos políticos y los organismos de derechos humanos los que enunciaron un discurso político en relación a la niñez; en los años 90 el discurso jurídico internacional de los derechos del niño - a partir de la adhesión argentina en 1990 a la Convención Internacional de los Derechos del Niño y de su incorporación en la Reforma Constitucional de 1994 - penetró el discurso político puso en las acciones de los gobiernos la enunciación de las necesidades y obligaciones del estado en relación a la infancia ${ }^{25}$. Por otra parte la cultura política se mediatizó pero también 
la cultura infantil y las imágenes de los niños se multiplicaron en los medios que se convirtieron en instancias de reconocimiento, desplazando al estado de la tarea simbólica de lograr el reconocimiento de la unidad de una sociedad (LECHNER, 1999).

Estos procesos requieren pensar la cuestión de la representación. El caso de los hijos de desaparecidos que se manifiesta a partir del retorno a la democracia fue paradigmático en relación con el problema de la representación ${ }^{26}$, pero esta asume una compleja significación en varios sentidos. Si durante buena parte del siglo XX, el estado, la iglesia y sectores de la sociedad civil, disputaron la representación de la población infantil, con la fuerza simbólica de los mecanismos de interpelación política de la niñez propia del ciclo del estado de bienestar, en estas últimas décadas se produjo una multiplicación y dispersión de agentes y discursos de representación (estatales, internacionales, de distintos sectores de la sociedad civil), un aumento de los fondos disponibles para la infancia ${ }^{27}$ y una crisis de sentido de esa representación debido al notorio cambio de la relación entre infancia y sociedad a partir del cambio del modelo de crecimiento y del aumento sin precedentes de la pobreza. Por contraste, se amplió un cada vez más sofisticado organigrama estatal, privado y comunitario, de programas especializados y de intervenciones técnicas que dieron forma a un verdadero aparato mixto de atención de la infancia ${ }^{28}$, mientras las políticas económicas de la década del 90 minaban la posibilidad del bienestar infantil.

El discurso especializado sobre la infancia no necesariamente redundó en una problematización del discurso político sobre la misma. En el caso de los medios lo que sí es notorio es cómo los especialistas (pedagogos, sociólogos, psicólogos) intervinieron en los medios como portavoces legítimos para esbozar interpretaciones frente a conflictos con niños y adolescentes que refieren a esa crisis de representación. Al mismo tiempo en no pocas ocasiones los representados (niños y jóvenes) son consultados en el marco de investigaciones o por los propios medios sobre tópicos específicos (democracia, paro docente, disciplina, etc.) ${ }^{29}$.

Estos acontecimientos fueron contemporáneos de diverso tipo de lecturas sobre la crisis de autoridad cultural del magisterio, de políticas oficiales de capacitación de los maestros y de evaluación de su rendimiento promovidas por la Reforma Educativa que colaboraron en cierta "culpabilización” de los mismos del atraso y deterioro de la educación ${ }^{30}$. Dos 
encuestas de la época se constituyen en fuentes privilegiadas para analizar el perfil del maestro tipo del sistema educativo pero también de los discursos que lo abordaron. La encuesta realizada por el UNESCO-IIPE (2001) indicó, entre otros datos, que la pobreza de los maestros triplicaba a la de los profesores, que tenían un nivel de instrucción superior al de sus padres pero se percibían peor y que sus consumos culturales mostraban un bajo nivel cultural. La encuesta realizada por CTERA (2001) se planteó debatir con los protocolos de lectura sobre el perfil docente planteados en la anterior encuesta y buscó la voz docente para relatar las condiciones en las cuales su trabajo se realizaba planteando que la docencia se llevaba adelante en una escuela carente de recursos básicos, que la pobreza había aumentado notoriamente siendo el maestro típico mujer y jefa de hogar, que predominaba una percepción crítica de la reforma educativa y que se reconocían indicadores notorios de deterioro y progresiva fragmentación del sistema educativo. En forma común y a pesar de las diferencias, lo que estas encuestas mostraron fue que los maestros de los niños argentinos eran mas pobres, con mayor formación que sus padres pero en un contexto de movilidad descendente que deterioró sus condiciones de vida y de trabajo y que su individualización o su mitificación resultaba improductiva en términos políticos.

Aun desde esa consensuada situación de precariedad, el discurso gremial dio forma a una posición política desde la cual interpeló al estado y a la sociedad en su conjunto. Si retomamos la noción de representación como hablar en nombre de representados ausentes en el momento de la representación y reconocemos -siguiendo a Laclau - el papel constitutivo del representante en la producción de la identidad del representado (véase CARLI, 2003a), la defensa de la educación pública llevada adelante en los años 90 debe ser leída por su capacidad de producir una interpretación general de la educación nacional, por poner en juego un modo de representación de la niñez argentina, anticipando en su reclamo los catastróficos datos de finales de la década. Un hecho que partió de un reclamo gremial logró excederlo articulando en la lucha docente otros elementos reivindicativos como el mejoramiento de la educación pública entendida a la vez como tradición a reivindicar y como lugar de socialización y crecimiento de la niñez argentina. También la lucha docente permitió señalar los límites estructurales de la reforma educativa (bajos salarios, deterioro de la infraestructura escolar, financiamiento insuficiente de la educación pública). 
La infancia como figura que alude a una temporalidad y un espacio de existencia común a restituir se convierte en parte de una interpelación política al mismo estado y a la sociedad en su conjunto por parte de educadores-maestros de escuelas públicas, pero también de educadores populares que en otras instituciones de la infancia (hogares, ong, etc.) eran testigos del aumento sin precedentes de la miseria infantil en el país.

El ciclo iniciado en 1983 se cerraría en el año 2001 con indicadores alarmantes para la sociedad argentina en su conjunto pero en particular para la población infantil. Más que nunca se hizo evidente que la cuestión de la infancia constituye un analizador de la sociedad en su conjunto y que la situación infantil constituye un espejo en el que es posible mirar las miserias, fracasos y traiciones de una configuración social, como sus horizontes de futuro en tanto nuevas y más complejas intervenciones políticas, colectivas y públicas radicalicen el sentido y la experiencia social de la democracia política para el conjunto de los niños nacidos y habitantes del territorio argentino.

\section{Conclusiones abiertas}

En este texto nos propusimos explorar el período 1983-2001 teniendo como analizador las transformaciones experimentadas por la niñez y los cambios producidos en la relación entre infancia y sociedad, infancia y educación e infancia y políticas. Esta investigación no pretendió ser exhaustiva, sino una ocasión para desplegar una serie de hipótesis sobre el pasado reciente y sobre las alternativas del tiempo presente.

La creciente diferenciación y complejidad de lo que denominamos las figuras de la infancia, a partir tanto del impacto de la polarización social y de los diversos discursos resultantes en la producción mediática y comercial, en el espacio educativo y en las políticas, indica como fenómeno histórico tanto la perdida de ciertos rasgos de homogeneidad y el aumento de la segmentación social de la situación infantil como la ausencia de consensos respecto de los modos de intervención para democratizar la situación de desigualdad planteada en el presente. La historia reciente muestra a su vez el cierre del ciclo histórico anterior dominado por procesos de integración social, por la expansión de la escolarización pública y por la presencia del estado como actor político productor tanto de 
mediaciones como de representaciones sociales para el conjunto de la población infantil. El período analizado, caracterizado - a pesar del carácter cíclico e inestable de la economía - por la estabilidad de la democracia como sistema de gobierno, expresa a su vez la escisión creciente entre el sentido social de la democracia política y el bienestar infantil, en tanto priman los modos de globalización de la noción de infancia y de individualización de las intervenciones colectivas que evitan una indagación de las consecuencias sociales sobre la niñez del empobrecimiento notorio de la sociedad argentina.

Las figuras de la infancia resultan de discursos cada vez más heterogéneos. En el período analizado la infancia devino en signo (político, comercial, mediático, etc.) y en motivo de producción de imágenes y representaciones de diverso tipo, a la vez que las condiciones de existencia de la población infantil en la Argentina presentaron los peores indicadores del siglo XX. Una perspectiva de historia de la infancia permite sostener en el presente la coexistencia conflictiva de temporalidades, concepciones y horizontes de expectativas de distintos ciclos históricos. El debate público se convierte más que nunca en el lugar donde dirimir nuevas formas de leer el pasado y el presente e intervenir en su modulación política, donde construir nuevas figuras de infancia que a la vez que recuperen en una totalidad de sentido la heterogeneidad de experiencias infantiles, proyecten hacia el futuro nuevos horizontes de justicia para la niñez en su conjunto.

\section{Referencias}

AGUERRONDO, Inés. Re-visión de la escuela actual. BsAs: Centro Editor de América Latina, 1987.

APDH. Sociedad democrática y derechos del niño. Buenos Aires, 1986.

ARIZAGA, María Cecilia. Prácticas e imaginario en el procesos de suburbanización. In: CUENYA, Beatriz; FIDEL, Carlos; HERZER, Hilda. Fragmentos sociales. Problemas urbanos de la Argentina, BsAs: Siglo Veintiuno, 2004.

BARBERO, Jesús Martín. La educación desde la comunicación. Colombia: Norma, 2003a.

BARBERO, Jesús Martín. Estética de los medios audiovisuales. In: XIRAU, Ramón; SOBREVILLA, David. Madrid: Trotta, 2003b.

BLEICHMAR, Silvia. La fundación de lo inconsciente. Buenos Aires: Amorrortu, 1999.

BONALDI, Pablo. Evolución de la muertes violentas en la Argentina. In: GAYOL, Sandra; KESSLER, Gabriel (Comp.) Violencias, delitos y justicias en la Argentina, UNGS. BsAs: Manantial, 2002.

CARLI, Sandra Niñez. Pedagogía y Política. Transformaciones de los discursos acerca de la 
infancia en la historia de la educación argentina. 1880-1955. BsAs: Editorial Miño y Dávila, 2002.

CARLI, Sandra Niñez. Educación pública. Historia y promesas. In: FELDFEBER, Miriam (Comp.) Los sentidos de lo público. Reflexiones desde el campo educativo, BsAs: Noveduc, 2003.

CARLI, Sandra Niñez. El problema de la representación. Balances y dilemas. In: Infancias y adolescencias. Teorías y experiencias en el borde. BsAs: Coedición Noveduc-CEM, 2003. Colección Ensayos y Experiencias.

CARLI, Sandra Niñez. Estudios sobre la infancia en la Argentina. Historia y análisis cultural. Ponencia presentada en el VI CONGRESO IBEROAMERICANO DE HISTORIA DE LA EDUCACIÓN LATINOAMERICANA, realizado en San Luis de Potosí, México, del 19 al 23 de mayo de 2003.

CARLI, Sandra Niñez. Los únicos privilegiados son los niños. Todo es Historia, n. 457, p. 58-65, agosto 2005.

CICIONI, Antonio. El movimiento de las charter schools. Una amenaza y una oportunidad para la educación pública argentina. Documento 7. Fundación Gobierno y Sociedad. Abril/1998.

CORAGGIO, José Luis. Las propuestas del Banco Mundial para la educación: ¿sentido oculto o problemas de concepción. In: CORAGGIO, José Luis; TORRES, Rosa María, La educación según el Banco Mundial. BsAs: Miño y Dávila editores, 1997.

CHARTIER, Roger. El mundo como representación. Barcelona: Gedisa, 1999.

CTA. Instituto de Estudios y Formación. Argentina: comunidad en riesgo. Infancia, adolescencia y juventud en mayo de 2002, Claudio Lozano. BsAs, Mayo de 2002.

CTA. Instituto de Estudios y Formación. Informe estadístico. Síntesis indicadores de salud y educación. Censo Nacional de Población, Hogares y Viviendas 2001. Base estadística IDEP/ATE/IDEF/CTA. Octubre/2003.

CTERA-IIPE MV. Consulta Nacional Docente. La educación argentina. Qué dicen los docentes? BsAs, 2001.

CTERA-IIPE MV. Informe sobre la situación de la educación en la Argentina 19912001. BsAs, 2003.

CTERA-IIPE MV. Prioridades para la construcción de políticas educativas públicas, 2004.

DE CERTAU, Michel. La invención de lo cotidiano. 1 Artes de hacer. México: Universidad Iberonamericana, 1996.

DEL CUETO Carla. Los únicos privilegiados. Estrategias educativas de las nuevas clases medias. Tesis (Maestría) Instituto de Altos Estudios Sociales, Universidad Nacional de General San Martín, 2003.

DE VEDIA, Mariano. La educación no espera. BsAs: Eudeba, 2005.

DOTRO, Valeria. Infancia y televisión. In: Revista del Instituto de Investigaciones en Ciencias de la Educación, Año VIII, n. 16, julio/2000.

FEIJOO, María del Carmen. Los gasoleros. Estrategias de consumo de los NUPO. In: MINUJÍN, Alberto y otros. Cuesta abajo. Los nuevos pobres: efectos de la crisis en la sociedad argentina, BsAs: UNICEF/Losada, 1995.

FEIJOO, María del Carmen. Nuevo país, nueva pobreza. BsAs: FCE, 2001.

FELDFEBER, Myriam. Estado y educación en la Argentina de los 90. In: ASCOLANI, 
Adrian. La educación en Argentina. Estudios de Historia, Rosario: Ediciones El Arca, 1999. FILK, Judith. Entre el parentesco y la política. Familia y dictadura, 1976-1983. BsAs: Editorial Biblos, 1997.

FILMUS, Daniel; MIRANDA, Ana. América Latina y Argentina en los 90: mas educación, menos trabajo=mas desigualdad. In: FILMUS, Daniel (Comp). Los noventa. Política, sociedad y cultura en América Latina y Argentina de fin de siglo, BsAs: Eudeba-Flacso, 1999.

FRIGERIO, Graciela. ¿Se han vuelto inútiles las instituciones educativas?. In: FILMUS, Daniel. Para qué sirve la escuela. BsAS: Tesis-Norma, 1993.

GALENDE, Emiliano. Diarios clínicos n 7: El niño y la historia. Buenos Aires: Lugar Editorial, 1994.

GARCIA CANCLINI, Nestor. La globalización imaginada. BsAs: Paidós, 1999.

GARCIA MENDEZ, Emilio. Prehistoria e historia del control socio-penal de la infancia: política jurídica y derechos humanos en América Latina. In: GARCIA MENDEZ, Emilio; BIANCHI, María del Carmen. Ser niño en América Latina. De las necesidades a los derechos. BsAs: Galerna, 1991.

GENTILI, Pablo. El Consenso de Washington y la crisis de la educación en América Latina. In: ALVAREZ URIA Y OTROS. Neoliberalismo versus democracia. Madrid: La Piqueta, 1998.

GONZALEZ, Horacio. El sujeto de la pobreza: un problema de la teoría social. In: MINUjÍN, Alberto y otros. Cuesta abajo. Los nuevos pobres: efectos de la crisis en la sociedad argentina. BsAs: UNICEF/Losada, 1995.

GUEMUREMAN, Silvia; DAROQUI, Alcira. La niñez ajusticiada. BsAs: Ediciones del Puerto, 2001.

HALL, Stuart. Introducción. Quién necesita identidad? In: HALL, Stuart; DU GAY, Paul (Comps). Cuestiones de identidad cultural. BsAs: Amorrortu editores, 2003.

HORNSTEIN, Luis. Trauma e historia. Actualidad Psicológica, Año XXX, n. 336, noviembre, 2005.

HOSBAWM, Eric. El sentido del pasado. In: HOSBAWM, Eric. El sentido de la historia. Barcelona: Crítica, 1998.

JAMESON, Fredric. Una modernidad singular. Ensayo sobre la ontología del presente, BsAs: Gedisa, 2002.

KESSLER, Gabriel. La experiencia escolar fragmentada. BsAs: IIPE/UNESCO, 2003.

LANDI, Oscar. Reconstrucciones. Las nuevas formas de la cultura política. BsAs: Puntosur, 1988.

LACAN, Jacques. El yo y el otro yo. In: LACAN, Jacques. El seminario de Jacques Lacan. Libro 1. Los Escritos técnicos de Freud 1953-1954. BsAs: Paidos, 1998.

LASH, Scott. Sociología del posmodernismo. BsAs: Amorrortu editores, 1997.

LECHNER, Norbert. Los condicionantes de la gobernabilidad democrática en América Latina de fin de siglo. In: FILMUS, Daniel (Comp). Los noventa. Política, sociedad y cultura en América Latina y Argentina de fin de siglo. BsAs: Eudeba-Flacso, 1999.

LEWCOWICZ, Ignacio; COREA, Cristina. Se acabó la infancia? Ensayos sobre la destitución de la niñez. BsAs: Lumen, 1999.

LIWSKI, Norberto. Los niños del silencio y la justicia. Buenos Aires: APDH, 1988.

LIWSKI, Norberto. La salud, derecho humano fundamental. In: GARCIA MENDEZ, 
Emilio; BIANCHI, María del Carmen. Ser niño en América Latina. De las necesidades a los derechos. BsAs: Galerna, 1991.

LUDMER, Josefina. Temporalidades del presente. Boletín/10, Centro de Estudios de Teoría y Crítica Literaria, Facultad de Humanidades y Artes de la Universidad Nacional de Rosario, 2002.

MAFFEI, Marta. Sobre la situación de los docentes en la Argentina. In: FRIGERIO, Graciela; POGGI, Margarita; GIANNONI, Mario (Comp.). Politicas, instituciones y actores en educación. BsAS: Coedición CEM-Novedades Educativas, 1997.

MARGULIS, Mario. La juventud es más que una palabra. Ensayos sobre cultura y juventud. BsAs: Editorial Biblos, 1996.

MARTINI, Stella. Agendas policiales de los medios en la Argentina: la exclusión como hecho natural. In: GAYOL, Sandra; KESSLER, Gabriel (Comp.) Violencias, delitos y justicias en la Argentina, BsAs: UNGS-Manantial, 2002.

MINISTERIO DE EDUCACIÓN, CIENCIA Y TECNOLOGÍA. Secretaria de Educación, Dirección Nacional de Información y Evaluación de la Calidad Educativa, Red Federal deInformación Educativa, Relevamientos 2001 y 2001.

MINUJÍN, Alberto. En la rodada. In: MINUJÍN, Alberto y otros. Cuesta abajo. Los nuevos pobres: efectos de la crisis en la sociedad argentina. BsAs: UNICEF/Losada, 1995. MINUJIN, Alberto. La gran exclusión? Vulnerabilidad y exclusión en América Latina. In: FILMUS, Daniel (Comp) Los noventa. Política, sociedad y cultura en América Latina y Argentina de fin de siglo. BsAs: Eudeba-Flacso, 1999.

MINUJIN, Alberto; KESSLER, Gabriel. La nueva pobreza en la Argentina. Buenos Aires: Planeta, 1995.

MINZI, Viviana. Mercado para la infancia o una infancia para el mercado. Transformaciones mundiales e impacto local. In: CARLI, Sandra (Dirección). Estudios sobre comunicación, educación y cultural. Una mirada a las transformaciones recientes de la Argentina, Buenos Aires: Editorial Stella-La Crujía ediciones, 2003.

NARODOWSKI, Mariano. Varias respuestas a diez objeciones efectuadas a las escuelas públicas autogobernadas. Un aporte al debate en la Argentina. Cuaderno 6. Fundación Gobierno y Sociedad. BsAs. Nov/1999a.

NARODOWSKI, Mariano. Hiperregulación de la escuela pública y desregulación de la escuela privada. El caso de los "consejos de convivencia". In: la Ciudad de BsAs. Documento 24. BsAs. nov/1999b.

NARODOWSKI, Mariano; NORES, Milagros. Quienes quedan y quienes salen? Características socioeconómicas en la composición de la matrícula en las escuelas públicas y en las escuelas privadas en la Argentina. Documento 31. Fundación Gobierno y Sociedad. Abril/2000.

NARODOWSKI, Mariano; NORES, Milagros; ANDRADA, Myriam. Nuevas tendencias en políticas educativas. Estado, Mercado y Escuela. Buenos Aires: Granica, 2002.

O’DONNELL, Guillermo. Contrapuntos. Ensayos escogidos sobre autoritarismo y democratización. BsAs: Paidós, 1997.

PELLEGRINELLI, Daniela. La república de los Niños. La función de los juguetes en las políticas del peronismo (1846-1955). Revista del Instituto de Investigaciones en Ciencias de la Educación, Año IX, n. 17, diciembre de 2000.

PORTANTIERO, Juan Carlos. El tiempo de la política. BsAs: Tesis Norma, 2000. 
PUIGGROS, Adriana. La fragmentación de la pedagogía y los problemas educativos latinoamericanos. In: PUIGGROS, Adriana. Democracia y autoritarismo en la pedagogía argentina y latinoamericana. BsAs: Galerna, 1986.

PUIGGROS, Adriana. Volver a educar. BsAs: Ariel, 1995.

PUIGGROS, Adriana. La otra reforma. Desde la educación menemista al fin de siglo, BsAs: Galerna, 1997.

QUEVEDO, Alberto. Política, medios y cultura en la Argentina de fin de siglo. In: FILMUS, Daniel (Comp) Los noventa. Política, sociedad y cultura en América Latina y Argentina de fin de siglo. BsAs: Eudeba-Flacso, 1999.

RAPOPORT, Mario. Tiempos de crisis, vientos de cambio. Argentina y el poder global. BsAs: Grupo Editorial Norma, 2002.

REDONDO, Patricia. Escuelas y pobreza. Entre el desasosiego y la obstinación. BsAs: Paidós, 2004.

RITZER, George. La Macdonalización de la sociedad. Un análisis de la racionalización en la vida cotidiana. Barcelona: Ariel, 1996.

SARLO, Beatriz. Escenas de la vida posmoderna. Intelectuales, arte y videocultura en la Argentina. BsAs: Ariel, 1994.

SENNET, Richard. El declive del hombre público. Barcelona: Península, 2002.

SIDICARO, Ricardo. La crisis del estado y los actores politicos y socioeconómicos en la Argentina (1989-2001). BsAs: Libros del Rojas, 2001.

SIDICARO, Ricardo. La distancia sociedad-partidos. Revista Argumentos, n. 1, Facultad de Ciencias Sociales, Instituto Gino Germani, BsAs, 2002.

SVAMPA, Maristella. Los que ganaron. La vida en los countries y barrios privados. BsAs: Biblos, 2001.

TEDESCO, Juan Carlos. Elementos para una sociología del currículum escolar en Argentina. In: TEDESCO; BRASLAVSKY; CARCIOFI. El proyecto educativo autoritario. Argentina. 1976-1982, BsAs: FLACSO, 1983.

TENTI FANFANI, Emilio. La educación básica y la "cuestión social" contemporánea. BsAs: IIPE/UNESCO, 2000.

TIRAMONTI, Guillermina. Modernización educativa de los '90. ¿El fin de la ilusión emancipadora? BsAs: Flacso-Temas Grupo Editorial, 2001.

TORRES, Rosa María. In: CORAGGIO; TORRES. La educación según el Banco Mundial. Buenos Aires: Miño y Dávila-UNICEF, 1997.

UNESCO-IIPE. Los docentes argentinos. Resultados de la encuesta nacional sobre la situación y la cultura de los docentes. BsAs, 2001.

VARELA, Julia. El triunfo de las pedagogías psicológicas. Cuadernos de Pedagogía, n. 298, diciembre de 1991.

VINELLI, Carolina. Campañas globales para problemas globales? El caso de la estrategia comunicacional de Unicef. II JORNADAS ACADÉMICAS DE CIENCIAS DE LA COMUNICACIÓN, 2000. 


\section{Notas}

${ }^{1}$ Entendemos por tiempo presente "una yuxtaposición o superposición de pasados y de futuros y una conjugación de temporalidades en movimiento cargadas de símbolos, signos y afectos" (Ludmer, 2002: 94).

2 La crisis del año 2001, que tuvo como detonante el corralito financiero dispuesto por el Ministro de Economía Domingo Cavallo y que provocó la renuncia del presidente De La Rúa, se plantea como acontecimiento que marca el cierre de la década del 90 pero a la vez de un ciclo histórico caracterizado por la expansión del capitalismo financiero.

3 Decimos traumático en tanto se hacen notorias las dificultades de simbolización de los abruptos y acelerados cambios económico-sociales producidos en un ciclo histórico corto. Como señala Horstein "pensar la historia es pensar en un determinismo ligado al pasado, pero también en un devenir relacionado con los traumas que reorganizarán los procesos en curso" (2005, p. 18).

4 Scott Lash define a la mercantilización como uno de los procesos de des-diferenciación en la cultura posmoderna que se vincula con la esfera del consumo y de la producción y que avanza en la actualidad sobre la educación y el ocio (1997, p. 69-78).

5 Lacan define al niño como "prodigiosamente abierto hacia todo lo que el adulto le aporta como sentido del mundo", destacando su permeabilidad frente al mito, la leyenda, los cuentos de hadas, la historia (1998, p. 83-84).

6 En 1974 el 60\% pobre y medio bajo de la población tenía el 33,5\% de los ingresos y el 40\% medio-alto y alto el 66,5\%, pero en 1999 el primer tramo solo poseía el 28,8\% y el segundo el 73,4\% (RAPOPORT, 2002, p. 258).

7 Alberto Morlaquetti, director de la Fundación Pelota de Trapo, relató en una entrevista que le hicimos la gradual e irreversible situación social de las familias que fue generando la salida a la calle de niños y adolescentes a partir de mediados de los años 70, sea para la búsqueda de aportes para la sobrevivencia, sea para no retornar al hogar. Mientras en los años 70 en un barrio como el de Avellaneda, en la provincia de BsAs, prácticamente no había chicos de la calle, en los 80 comenzó el deterioro de las familias por la falta de trabajo que provocaría una mayor precariedad y violencia en el vínculo entre padres e hijos y en muchos casos la salida de los chicos a la calle. Ana Pagano, otra educadora entrevistada, que trabajaba en barrios y villas desde los años 70, también recuerda el aumento de niños mendigos en los ochenta y el impacto creciente de la droga sobre los adolescentes en la Provincia de BsAs.

8 Cabe recordar aquí el relato de una educadora sobre la predilección de los chicos de la calle por las zapatillas de marca y los esfuerzos monetarios realizados para acceder a ellas. 9 Según una Encuesta realizada en 1999 sobre 1800 casos por Rosendo Fraga, mencionada en "La opinión pública en los 90: la sociedad que cambia" en Todo es Historia n. 389, dic/1999.

10 Se produce durante la década del 90 un proceso de transnacionalización de la televisión con la replicación de formatos, la expansión de los canales de cable que amplían la oferta televisiva para niños en cantidad y tiempo y la publicidad como principal fuente de financiamiento de los medios. 
11 La telenovela infantil Chiquititas (vease DOTRO, 2000), representativa de la nueva televisión de los años 90, condensó en su puesta en escena algunos de estos procesos al ficcionalizar los contrastes sociales de la vida infantil. Dicha telenovela, entre otros productos, participa en el proceso más amplio de expansión global de los imaginarios (GARCÍA CANCLINI, 1999, p. 33), en este caso sobre la infancia.

12 Nos referimos a un archivo hemerográfico conformado por una selección de noticias de Pagina 12 y de Clarín en el período 1983-2001.

13 El Programa "Policías en Acción", producido por Endemol, en la que los menores son expuestos a una espectáculo mediático en el medio de situaciones cotidianas de gran conflictividad, es sólo una muestra.

14 Cabe mencionar la serie de casos paradigmáticos como Jimena Hernández, María Soledad Morales, Nair Mostafá, etc.

15 La tasa neta de escolarización en primaria en 1980 era de 89,6\% y en 1991 de 95,3\%. (TIRAMONTI, 1995, p. 27).

16 Como destacó Emilia Ferreiro en una entrevista "si este niño no tomaba su lugar en la escenografía escolar, hubiéramos seguido con discursos bastante vacíos....". El desarrollo de la teoría constructivista., tanto en el testimonio de Emilia Ferreiro como en el de otra entrevistada, Susana Fernández, permite comprender los alcances de la investigación iniciada en los años 60 en la Facultad de Filosofía y Letras y de sus derivaciones pedagógicas en los años 80 a partir del nuevo interés que el niño ocupa como objeto mismo de investigación (sus teorías sobre la escritura).

17 Datos del año 2001 plantearon a nivel nacional que el 78,0\% de los establecimientos educativos son públicos y el $22 \%$ son privados, asistiendo un $76,6 \%$ de alumnos a los primeros y un 23,4\% a los segundos, según datos del año 2002 (MINISTERIO DE EDUCACIÓN, 2002).

18 Los especialistas que promovieron estas experiencias reconocen la existencia de estudios que plantearon la relación entre las charter y la segregación socioeconómica y el refuerzo de la segregación racial en Estados Unidos (NARODOWSKI, 1999, p. 3).

19 La concepción de educación básica se apartó de la acordada en 1990 en la Conferencia Mundial de Educación para Todos, en la que había una visión ampliada que incluía a otros sujetos y modalidades educativas y duraba toda la vida (TORRES, 1997, p. 82).

20 Recordemos que en la Convención Constituyente de 1994 se produjo un álgido debate en torno la noción de igualdad, que quedó desplazada por la noción de equidad (véase PUIGGRÓS, 1995).

21 Se señala que el criterio predominante en el gasto en educación ha sido la restricción presupuestaria (MORDUCHOWICZ, 2002, p. 16). En otras palabras, Puiggrós refirió entonces a "la parábola del ajuste" (1997). Por último, destaquemos sólo un dato: a pesar del aumento de la inversión educativa durante los 90 el gasto por alumno continuó siendo alarmantemente bajo, siendo en la escuela primaria 16 veces menor que en los países de la OCDE (en FILMUS; MIRANDOA, 1999, p. 117).

22 Un caso complejo ha sido la obligatoriedad de la sala de 5 años del jardín de infantes, 
que a la vez que puede ser concebida como un avance no contó con condiciones institucionales para ser efectivizada.

23 Se verifica una común cuestionamiento al papel homogeneizante del sistema educativo en las posiciones educativas postdictadura, en estudios sobre la educación desde la crítica foucaultiana, en la teoría financiera aplicada a educación y en posiciones de defensa de la introducción de mecanismos de mercado en educación. Si bien estos discursos no son necesariamente convergentes, evitan la polisemia del concepto homogeneidad que queda congelado en ciertas expresiones históricas pasadas.

24 "Los diferentes principios de orden predominantes en la sociedad en un momento dado, han logrado delimitar lo que es y lo que no es asunto político porque también hacen prevalecer determinadas concepciones sobre la cultura, las relaciones que debe guardar con la vida publica y la privada de los individuos y los criterios de autoridad que definen las jerarquías en el campo intelectual" (LANDI, 1988, p. 207).

25 Emilio García Mendez, referente del campo jurídico, planteaba a principios de los 90 que "es preciso politizar y al mismo tiempo despartidizar profundamente la cuestión de la infancia. Politizar en el sentido de que ninguna variable debe ser dejada de lado en el momento de trazar las estrategias de acción. Despartidizar en el sentido de que es necesario encontrar los mecanismos institucionales adecuados que consagren la cuestión de la infancia como cuestión de toda la sociedad” (GARCÍA MENDEZ, 1991, p. 18).

26 "Si convenimos en que estos niños han sido víctimas de violaciones flagrantes de sus derechos, una de las mayores privaciones es la pérdida de representación necesaria original: la que ejercen los padres respecto de sus hijos menores de edad, derivada del derecho natural de la descendencia y la filiación biológica" sostenían Bokser y Guarino (1992, p. 77), dando cuenta que el problema de representación del menor se dirimía entre la filiación natural-biológica, el estado de familia supuestamente creado y el resultante de la comisión de otros delitos contra el niños que se intenta representar (1992, p. 79).

27 Este aumento de fondos nacionales e internacionales, que multiplicaron la cantidad de instituciones para menores en riesgo, dieron lugar a sonados casos de corrupción en años recientes.

28 La década del 90 se caracteriza por medidas tendientes a aplicar en cada estado lo convenido por la Convención de los Derechos del Niño y ello tiene efectos en la ampliación del organigrama estatal, como la creación por decreto del Consejo Nacional del Menor y la Familia dentro del Ministerio de Salud y Acción Social, el cual llegaba para reemplazar a la Secretaría de Desarrollo Humano y Familia.

29 Cabe mencionar aquí el libro Cartas al Presidente (1987) compilado por Alicia Entel y Cecilia Braslavsky, que reunió mas de 1000 cartas de alumnos de escuelas primarias y secundarias dirigidas al entonces presidente Alfonsín.

30 Marta Maffei sostenía en un texto publicado 1997 que el modelo educativo de la Reforma coexistía con el ajuste estructural y en relación a los docentes "por un lado se desacredita al maestro y por el otro se le exige cada vez más un rol protagónico, sin considerar en absoluto las condiciones en que se ejerce la tarea cotidiana" (MAFFEI, 1997, p. 222). 
Recebido: 27/10/2009

Aprovado: 25/11/2009

Contato:

Universidad de Buenos Aires Facultad de Ciências Sociales

Marcelo T. de Alvear, 2230

Capital Federal

CP C1122AAJ

Buenos Aires/Argentina 
